Vidmantas Tütlys

Lithuania

Genutè Gedviliené

Lithuania

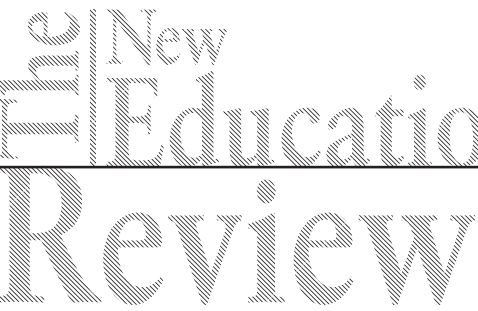

Rasa Didžiuliené

Lithuania

\title{
The Influence of Teacher Professional Burnout on Professional Satisfaction in Professional Career Development
}

DOI: 10.15804/tner.2021.63.1.18

\begin{abstract}
Teacher professional activity, its quality and work efficiency are conditioned by social changes and educational reforms. The following question guides this analysis: What is the impact of professional burnout and professional satisfaction on the development of teachers' professional career? The analysis of scientific literature was selected for the theoretical explanation of the research problem as well as a quantitative research method was selected for the empirical research. The indicators on the questionnaire scales provided an opportunity to determine the links between Lithuanian teachers' professional burnout and vocational satisfaction according to different stress dimensions. Statistical analyses were performed using IBM SPSS 23. The results of theoretical and empirical research made it possible to establish the main factors affecting teachers' professional career:1) significantly reduced ability to work, productivity, lack of work-life balance and self-control at work (professional burnout factors); 2) personal fulfilment and self-realisation and wishing to contribute to social well-being (professional satisfaction factors).
\end{abstract}

Key words: Teacher Professional Burnout, Professional Satisfaction 


\section{Introduction}

Teachers are facing new challenges that change the way they interact with the environment, change their needs, and present long-term new changes. The article discusses the extent to which professional burnout manifests itself in the Lithuanian teacher community as a whole, and its influence on teachers professional satisfaction.

The aim of the research is to reveal the influence of professional burnout and professional satisfaction on the development of teachers' professional career.

The problem: The research aims to discuss the following questions: what is the strong/weak expression of burnout in the Lithuanian teacher community, what is its relationship with teachers' professional satisfaction; and what influence does it have on the development of teachers' professional career.

Methods: To discuss the problem, an analysis of scientific literature and a quantitative research strategy were used in conjunction with a written survey of general education school teachers. The indicators of the survey scales provided an opportunity to determine the impact of professional burnout and professional satisfaction among Lithuanian teachers on their professional career depending on different factors.

\section{Theoretical framework}

\section{Teachers' Professional Career}

Policy changes and stress at work are challenges that teachers face when planning their careers (Schaefer, 2013). The professional career research has provided insights into the factors that contribute to high-quality and effective professional development of teachers, which improves teaching and student achievement (Pianta et al., 2008; Desimone, 2009; Downer et al., 2009; Hill et al., 2013;, 2015; Cordingley et al., 2015; Brown \& Weber, 2016; Abessolo, Rossier \& Hirschi, 2017). Research suggests that career development is seen as a "whole-life" endeavour, necessarily encompassing the myriad facets of a person's life that may influence their career (Litano \& Major, 2016). Differences between expectations in professional life and the realities of teachers' work cause professional frustration.

\section{Teacher Professional Burnout}

Professional burnout is associated with attrition and reduced professional satisfaction (Kelchtermans \& Ballet, 2002; Ballantyne, 2005, 2007; Skaalvik \& Skaalvik, 
2010). As work-related psychological and physical stress remains, professional satisfaction is reduced and professional commitment is lost (Szempruch, 2018). Teachers' professional activity, its quality and work efficiency are determined by social changes and educational reforms. Changing roles of teachers affect professional satisfaction and social well-being of teachers. This can be a cause of constant teacher professional burnout. The professional burnout is a syndrome resulting from chronic work-related stress, with symptoms characterized by "feelings of energy depletion or exhaustion; increased mental distance from one's job or feelings of negativism or cynicism related to one's job and reduced professional efficacy" (WHO, 2019). The teacher professional burnout is dissatisfaction of some needs, in other words, increasing frustration with mental and physical symptoms that reduce self-esteem (Vollmer, 1998); long-term human response to constant emotional and interpersonal stress at work (Maslach, 2003). Research on professional burnout provides an opportunity to identify problems in teachers' career and employ timely preventive solutions that enhance career development and success.

\section{Teachers' Professional Satisfaction}

Professional satisfaction is a positive emotional state determined by the attitude towards the work done (Arnold, 2005); the totality of positive personal attitudes to work (Seta, 2000); and an evaluative attitude towards one's work or a particular work situation (Weiss, 2002). Professional satisfaction contributes to teachers' well-being because satisfied teachers are less sensitive to stress and burnout (Toropova, Myrberg \& Johansson, 2020). Such teachers also offer higher quality learning support for students (Kunter et al., 2013). The teachers satisfied with their profession succeed in developing emotional skills needed to manage social relationships in the classroom and to foster proper learning atmosphere along with students' academic achievement (Wanless et al., 2015, Rodriguez, Condom-Bosch, Ruiz \& Oliver, 2020). Professional satisfaction is a teacher's sense of success on the job. This is influenced by the following factors: the nature of work; salary; advancement opportunities; management; work groups and work conditions (Aziri, 2011). Professional satisfaction leads to higher motivation, dedication to work, lower teacher turnover and contributes to career development. 


\section{Methodology}

An anonymous survey was conducted during the study. Respondents assessed two variables in the questionnaire - teachers' professional burnout (46 statements) and teachers' professional satisfaction (16 statements). Teachers had the opportunity to rate the intensity of their attitudes according to the Likert (1932) linear scale (from 1 - "not at all important" to 5 - "very important").

Study participants and study sample. The research set consisted of all 24,109 teachers who work in Lithuania (2019-2020 ŠVIS data). Knowing the values of population, probability and error, the size of a representative research sample was calculated (95\% probability), where the value of error was 0.05 , i.e. 381 teachers. A total of 398 teachers participated in the survey (the representative sample of the survey - 381 respondents): 334 (84\%) female and 64 (16\%) male. This corresponds to the real relative distribution of male and female teachers in the Lithuanian teachers' community. The average length of service of the teachers participating in the study was $45.36 \pm 13.14$ years.

Organization of the study. The survey was conducted in November-December 2019 at the Lithuanian general education institutions. The teachers who participated in the survey had the opportunity to fill in the questionnaire online: the questionnaire was published on the freely available online survey portal www. apklausa.lt. The link to the survey together with a short description of the study had been sent by e-mail to Lithuanian general education schools.

Data analysis. A statistical data analysis was performed using the Social Science Statistics Package (SPSS 23) for Windows. The reliability of the scales was proved by estimating the Cronbach's Alpha coefficients $\left(\alpha^{1}=0.971\right.$ and $\left.\alpha^{2}=0.922\right)$ for the variables Teacher's Professional Burnout ${ }^{1}$ and Teacher's Professional Satisfaction ${ }^{2}$.

Research ethics. The study was conducted on the basis of the instrument proposed by D. Bubeliene (2010). The participants were informed about ethical procedures, data anonymity and confidentiality.

\section{Research findings}

The analysis of the data disclosed the influence of occupational burnout on the professional satisfaction of general education school teachers. Professional satisfaction is determined by internal (age, gender, level of education, length of service, career opportunities, recognition) and external (quality of management, salary, job content, co-workers, working conditions) factors. Professional burnout 
occurs in the work situations and is often defined by the persons' attitude to work. It has been hypothesized that male teachers and female teachers view professional burnout and professional satisfaction differently.

Table 1. Distribution of professional burnout and teachers' professional satisfaction by gender

\begin{tabular}{llllc}
\hline \multicolumn{1}{c}{ Variables } & \multicolumn{1}{c}{ Gender } & N & Mean \pm SD & p \\
\hline Professional satisfaction_total & Male & 64 & $46.7 \pm 10.2$ & \multirow{2}{*}{0.498} \\
\cline { 2 - 4 } & Female & 334 & $45.1 \pm 13.6$ & \\
\hline Professional burnout_total & Male & 64 & $121.3 \pm 36.3$ & \multirow{2}{*}{0.827} \\
\cline { 2 - 4 } & Female & 334 & $119.6 \pm 37.2$ & \\
\hline
\end{tabular}

In the study of attitudes towards professional satisfaction by female and male respondents, it was found (Table 1 ) that the difference was not statistically significant ( $\mathrm{p}=0.498)$. In the study of attitudes towards occupational burnout by female and male respondents, it was found (Table 1) that the difference was not statistically significant $(\mathrm{p}=0.827)$ either. It can be assumed that female and male teachers have similar attitudes to both professional burnout and professional satisfaction.

Table 2. Distribution of teachers' professional satisfaction and professional burnout according to the work experience of teachers

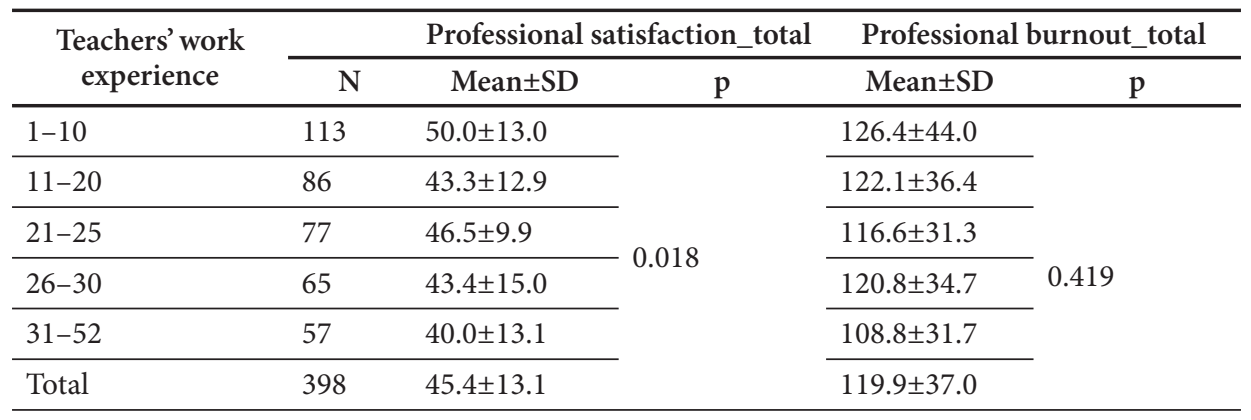

During the survey of Lithuanian general education school teachers, it was clarified at what stage in teachers' career professional satisfaction dominates among teachers and how professional burnout depends on the teachers' work experience. Both the joy of teaching $($ mean $=50)$ and the signs of burnout (mean=126) are most often experienced by teachers, who have been working at school for the first 10 years (Table 2). It is interesting to note that lower profes- 
sional satisfaction (mean $=40$ ), but at the same time less stress, fewer signs of professional burnout $($ mean $=108)$ are identified among the teachers who have worked at school for the longest time (more than 30 years).

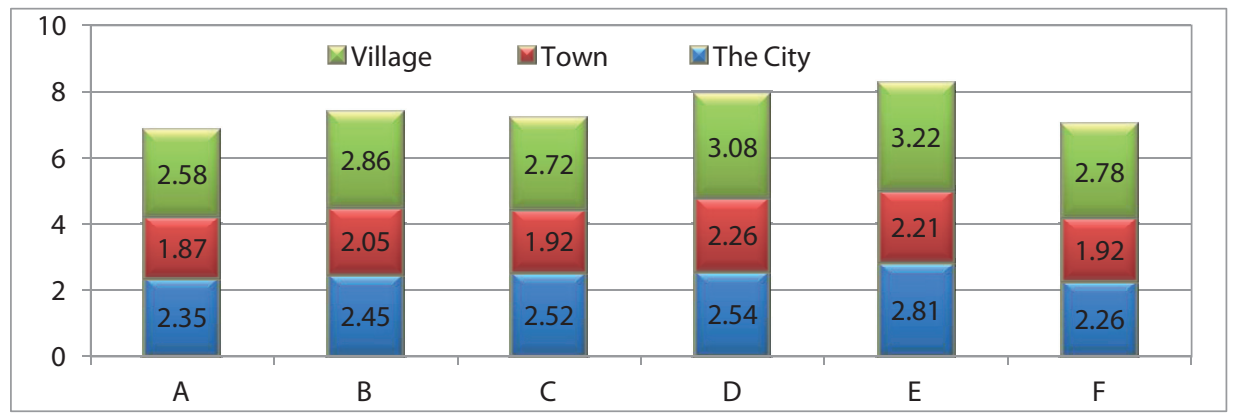

Fig. 1. Respondents' opinions about professional burnout by school location

Values in Figure 1:

A - There is no strength at all to work;

B - I am losing my abilities needed for work;

C - The efficiency and effectiveness of my work have declined recently;

D - My moods change a lot, the elevated feelings suddenly turn into sadness;

E - I fail to rest, to recover;

F - I constantly blame myself; I am ashamed, I feel guilty that I am a bad teacher;

Teachers participating in the survey provided the statements that best corresponded to the teacher professional burnout, the average estimate of the statements in each group (City, Town and Village) was then calculated. The results show that teacher professional burnout is most often associated with fatigue factors:

- In the City schools: "I fail to rest, to recover" (the average estimate - 2.81); "My moods change a lot, the elevated feelings suddenly turn into sadness" (the average estimate - 2.54); "the efficiency and effectiveness of my work have declined" (the average professional burnout is most often associated with fatigue factors estimate - 2.52) and "I am losing my abilities needed for work" (the average estimate - 2.45), and the lowest figure - "I think that the work of all conspired against me" (the average estimate - 1.52).

- In the Town schools: "My moods change a lot, the elevated feelings suddenly turn into sadness" (the average estimate - 2.26); "I fail to rest, to recover" (the average estimate -2.21) and "I am losing my abilities needed for work" (the average estimate - 2.05), and the lowest figure - "I think that the work of all conspired against me"(the average estimate -1.33 ). 
- In the Village schools: "I fail to rest, to recover" (the average estimate - 3.22); "My moods change a lot, the elevated feelings suddenly turn into sadness" (the average estimate - 3.08); "I am losing my abilities needed for work" (the average estimate -2.86 ) and "I constantly blame myself; I am ashamed, I feel guilty that I am a bad teacher" (the average estimate - 2.78).

The choices by study participants in terms of the factors that most influence professional burnout were similar, regardless of the location of the school (City, Town and Village) they represent. The following statements dominated: "I fail to rest, to recover"; "My moods change a lot, the elevated feelings suddenly turn into sadness" and "I am losing my abilities needed for work".

There is no statistically significant difference in the burnout of teachers working at schools in different areas $(\mathrm{p}=0.101)$. In summary, it can be assumed that the study participants' professional burnout does not depend on the area where the school is located.

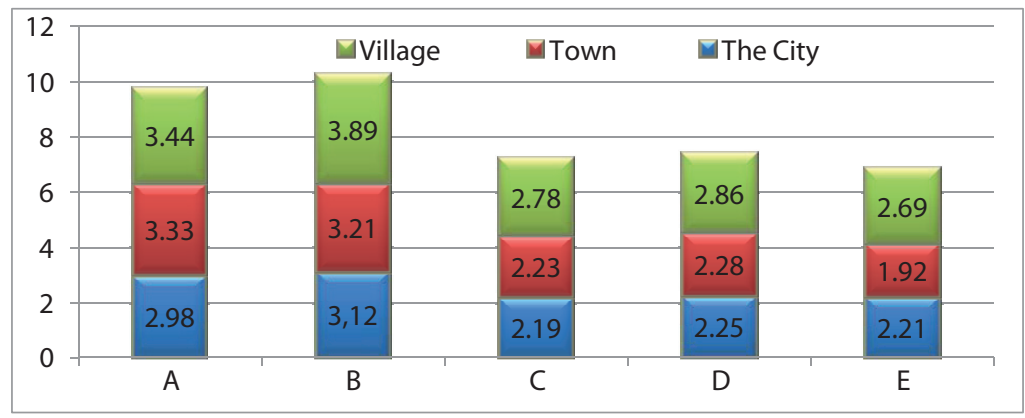

Fig. 2. Respondents' opinions about the professional satisfaction by school location

Values in Figure 2:

A - I enjoy being a teacher;

$\mathrm{B}$ - No other profession provides so much satisfaction as being a teacher;

$\mathrm{C}$ - I am pleased that the teaching profession is very creative; I constantly need to change something, innovate;

D - The teaching profession is very rewarding, because the teacher works with children and young people;

$\mathrm{E}$ - No matter what is happening in life, I leave those problems behind, because children have to learn only in a positive environment.

The survey participants provided the statements that best corresponded to the teachers' professional satisfaction, the average estimate of the statements in each group was then calculated. The results show that teachers' professional satisfaction 
is most often associated with fatigue factors, which are equally often mentioned by all respondents, regardless of where their place of work is located:

- In the City schools: "No other profession provides so much satisfaction as being a teacher" (the average estimate - 3.12) and "I enjoy being a teacher" (the average estimate - 2.98).

- In the Town schools: "I enjoy being a teacher" (the average estimate - 3.33) and "No other profession provides so much satisfaction as being a teacher" (the average estimate - 3.21)

- In the Village schools: "No other profession provides so much satisfaction as being a teacher" (the average estimate -3.89 ) and "I enjoy being a teacher" (the average estimate - 3.44).

The choices by study participants in terms of the factors that most influence professional satisfaction were similar, regardless of the location of the school (City, Town and Village) they represent. The following two factors dominated: "No other profession provides so much satisfaction as being a teacher" and "I enjoy being a teacher".

In summary, it can be assumed that the location of schools influences teachers' professional satisfaction $(\mathrm{p}=0.039)$. There are more teachers in the City/Town, who want to develop their careers, and teachers in Village schools should be encouraged to do so more often.

\section{Discussion}

Over the last decade, research has shown that professional burnout and professional satisfaction have a significant impact on choosing a teaching profession and teachers' career development. This study aims to understand the role of the work environment in creating a positive teaching and learning environment at school and in promoting the career development of teachers.

Research has also shown that professional burnout manifests itself in exhaustion, depersonalization, and diminished personal achievement. The teacher is intensely confronted with the students' problems, while at the same time feeling responsible for their own destiny and begins to blame themselves for not providing effective help in a timely manner.

The results of studies have demonstrated that in the stage of professional burnout, a person feels energy loss, headaches, anger, fatigue, insomnia, hypersensitivity, resistance to sudden reactions and impulsivity. Emotional exhaustion draws attention to the fact that a person performs a given job above their limits while 
not receiving support from others. The present study has revealed that among the factors already listed, teacher burnout manifests itself in the lack of empathy and cynicism, decreased personal achievement, and professional satisfaction that lead to feelings of meaninglessness and resignation. Assessing the opinions of the research participants, there was a tendency to evaluate oneself negatively, especially in terms of professional competence and work efficiency. This leads to evaluating oneself as an incompetent and inefficient person who is unable to perform one's professional tasks properly. A survey of Lithuanian general education school teachers has revealed that both the joy of a teacher's work (average $=50$ ) and the signs of burnout (average $=126$ ) are most often experienced by teachers during their first 10 years working at school (Table 2). It is interesting to note that the teachers who have worked at school for the longest time (more than 30 years) are less likely to experience professional burnout (mean $=108$ ). The choices by study participants in terms of the factors that most influence professional burnout were similar, regardless of the location of the school (City, Town and Village) they represent. The following factors dominated: "I fail to rest, to recover" and "My moods change a lot, the elevated feelings suddenly turn into sadness, my work capacity has suddenly decreased". There is no statistically significant difference in the professional burnout of teachers working in schools in different areas $(\mathrm{p}=0.101)$. In summary, it can be assumed that the study participants' professional burnout does not depend on the area where the school is located.

The survey examined teachers in general education schools who expressed their views on burnout and job satisfaction in professional life of a teacher. One part of the survey revealed the main areas where there were signs of burnout. It is worrying that, according to the results of the study, every fifth teacher noted a very high or a high sense of burnout. That is why it is important to prepare future teachers - already at the learning stage - to master unusual educational situations and learn to apply strategies to prevent the professional burnout.

Professional satisfaction research allows identifying teachers' motivational state and factors that cause positive emotions at work. Professional satisfaction is multifaceted, so each component contributes differently to shaping teachers' sense of professional satisfaction. The research shows that teachers are satisfied when their expectations are met, their wishes are fulfilled and their demands are heard. Professional satisfaction is a positive emotional state that arises from evaluating one's work and work experience. The survey of teachers revealed that teachers' professional satisfaction is often associated with factors, which are equally often mentioned by all respondents, regardless of the location of the school (City, Town and Village). The following two statements dominated: "No other profession 
provides so much satisfaction as being a teacher"| and "I enjoy being a teacher". Although respondents identified essentially the same factors that characterize professional satisfaction, the data show that teacher professional satisfaction was statistically significant in different school locations $(\mathrm{p}=0.039)$. A high level of professional satisfaction is associated not only with the development of professional competencies, but also with the added value of improving teachers' professional performance irrespective of the location of the school. It is therefore necessary to provide training to promote subjective professional satisfaction. The main content could be the regulation of positive and negative emotions, time management, and the application of positive psychological interventions. Teacher training can be a motivating starting point for school development processes to promote teacher professional satisfaction.

In today's dynamic career context, teacher professional satisfaction plays an important role in the management and development of professional careers. Professional satisfaction helps teachers differentiate their needs and is important for understanding career paths and enhancing careers.

\section{Conclusions}

- Professional satisfaction in the work of a teacher depends on the length of service: teachers under 10 years of work experience enjoy their work most, whereas teachers who work at school for the longest time experience least joy with their work. The attitudes of male and female teachers to professional satisfaction and burnout are similar.

- Professional career of teachers is influenced by professional burnout and the most frequently mentioned manifestations of burnout are as follows: "I find it difficult to get some rest, to recover"; "The elevated feelings suddenly turn into sadness"; and "My work capacity has suddenly decreased". Professional satisfaction defined by the statements "No other profession provides so much satisfaction as being a teacher" or "I enjoy being a teacher" helps to overcome professional obstacles and challenges and provides conditions for improving teachers' professional career.

- The choices by study participants concerning the factors most influencing professional satisfaction are similar, regardless of the location of the school (urban or rural) in which they work. There are many teachers in urban schools who are satisfied with their work, whereas teachers in small towns and rural schools lack professional career opportunities. 


\section{References}

Abessolo, M., Rossier, J. \& Hirschi, A. (2017). Basic Values, Career Orientations, and Career Anchors: Empirical Investigation of Relationships. Frontiers in Psychology, 8,1556. doi: 10.3389/fpsyg.2017.01556 .

Ballantyne, J. \& Retell, J. (2020). Teaching Careers: Exploring Links Between Well-Being, Burnout, Self-Efficacy and Praxis Shock. Frontiers in Psychology, 10, 2255. Doi: 10.3389/ fpsyg.2019.02255.

Denton, E., Chaplin, W.F., \& Wall, M. (2013). Teacher burnout: A comparison of two cultures using confirmatory factor and item response models. International Journal of Quantitative Research in Education, 1(2), 147-166.

Szempruch, J. (2018). Feeling of Professional Burnout in Teachers of Secondary Schools. New Educational Review, 54, 219-230. Doi: 10.15804/tner.2018.54.4.18.

Schaefer, L. (2013). Beginning teacher attrition: a question of identity making and identity shifting. Teachers and Teaching, 19(3), 260-274. Doi: 10.1080/13540602.2012.754159.

Stočkus, A. (2014). Prevention and Reduction of Physical Education Teachers' Burnout: Results of an Educational Project. Tiltai. ISSN 1392-3137.

Toropova, A., Myrberg, E. \& Johansson, S. (2020). Teacher Job Satisfaction: The Importance of School Working Conditions and Teacher Characteristics. Educational Review, 72. Doi: 10.1080/00131911.2019.1705247.

Weiss, H.M. (2002). Deconstructing Job Satisfaction: Separating Evaluations, Beliefs and Affective Experiences. Human Resources Management Review, 12 (2), 173-194. Doi: 10.1016/S1053-4822(02)00045-1.

WHO (28 May 2019). Burnout an "occupational phenomenon": International Classification of Diseases. 